\title{
PRESIDENT'S COLUMN
}

\section{Teachers and Doctors: Measurement is Killing Our Profession}

Frederick M. Chen, MD, MPH

(Fam Med. 2019;51(8):703-4.)

doi: 10.22454/FamMed.2019.213937

W hat's in a name? The Society of Teachers of Family Medicine was founded more than 50 years ago, predating even our specialty. A society is an "organization of people formed for a specific purpose." ${ }^{1}$ But it's no accident that society also connotes our larger social connection of community, culture, families, and population. I think it was with this intent that STFM was so named.

For many of us, our primary professional identity is that of family physician. We take great pride in our training, our culture, our daily work, and it is appropriate that we do so. But consider for a moment the "T" in STFM.

STFM brings us together because we are teachers of family medicine. What sets us apart as teachers? How do we think of ourselves as teachers? What has drawn us to teaching?

Teaching, of course, has its own science, its own history, and its own language that we have assumed for our professional training. Some of us have undertaken training in educational theory or gained a better understanding of the language and design of learning and education. Many of us conduct educational research and evaluation, to better define the successes and drawbacks of educational interventions.

Our identity as teachers is and should be intimately linked to our identity as physicians. Our motivation to teach is often the same as our motivation to heal-to help, to lead, to mentor, to coach.

It's troubling how both education and medicine are laboring under similar pressures. ${ }^{2}$
Both professions have succumbed to a culture of measurement, oftentimes coloring if not dictating how we teach and doctor. The culture of measurement has been enabled by the growth of capacity for measurement, evidenced by everyday terms like big data, population health, and the promise of artificial intelligence.

In K-12 education, this has led to an overreliance on testing and test results as one of the main markers of educational success. Principals and schools now look first to their testing outcome data to determine curricular needs, teaching resources, and how they compare. In medicine, of course, we are beset by a myriad of quality measures, all inexplicably tied to payment bundles and shared savings, none more tyrannical than the ultimate measure: productivity, relative value units, and volume.

Not everything that counts can be counted, and not everything that can be counted counts. ${ }^{3}$

Teachers and doctors are in a struggle to maintain motivation to do what we do. Our motivations are personal, but they are also shared. We are rarely sustained by external motivation-class, status, wealth. We are in fact sustained by meaning and personal connection, by the quality of relationships over time, by community and engagement. These connections are why we teach and doctor.

The pressure of measurement will not disappear. It is a systemic reaction to a professional history of the power of the claim "we know what we're doing." But we must acknowledge how measurement has affected our daily 
work. We must understand its motivation and engage in ways to change it for the better. We must continue to value outcomes that are unmeasurable, such as meaning and relationship. These are STFM's priorities, and we need your voice and support to meet them. The future of our professions-teaching and medicine-depend on it.

CORRESPONDENCE: Address correspondence to Dr Frederick Chen, Department of Family Medicine, University of Washington School of Medicine, 325 9th Ave, Seattle, WA 98104. fchen@u.washington.edu.

\section{References}

1. Society. Lexico Dictionary [online]. 2019. https://www.lexico. com/en/definition/society.

2. Watcher RM. How measurement fails doctors and teachers. The New York Times. January 16, 2016. https://www.nytimes.com/2016/01/17/opinion/sunday/how-measurementfails-doctors-and-teachers.html. Accessed August 14, 2019.

3. Hilliard J. The current and potential use of course examinations. JAMA. 1966;198(3):289-290. 